\title{
Characteristics of the Antarctic surface mass balance, 1958-2002, using a regional atmospheric climate model
}

\author{
W.J. VAN DE BERG,${ }^{1}$ M.R. VAN DEN BROEKE, ${ }^{1}$ C.H. REIJMER, ${ }^{1}$ E. VAN MEIJGAARD ${ }^{2}$ \\ ${ }^{1}$ Institute for Marine and Atmospheric Research Utrecht, PO Box 80.005, Utrecht University, Princetonplein 5, \\ 3584 CC Utrecht, The Netherlands \\ E-mail: w.j.vandeberg@phys.uu.nl \\ ${ }^{2}$ Royal Netherlands Meteorological Institute, Postbus 201, 3730 AE de Bilt, The Netherlands
}

\begin{abstract}
Temporal and spatial characteristics of the Antarctic specific surface mass balance (SSMB) are presented, including its components solid precipitation, sublimation/deposition and melt. For this purpose, we use the output of a regional atmospheric climate model (RACMO2/ANT, horizontal resolution of $\sim 55 \mathrm{~km}$ ) for the period 1958-2002. RACMO2/ANT uses European Centre for MediumRange Weather Forecasts (ECMWF) 40 year re-analysis (ERA-40) fields as forcing at the lateral boundaries. RACMO2/ANT underestimates SSMB in the high interior of East and West Antarctica and overestimates SSMB on the steep coastal slopes. Otherwise, the modeled spatial pattern of SSMB is in good qualitative agreement with recent compilations of in situ observations. Large-scale patterns, like the precipitation shadow effect of the Antarctic Peninsula, are well reproduced, and mesoscale SSMB patterns, such as the strong precipitation gradients on Law Dome, are well represented in the model. The integrated SSMB over the grounded ice sheet is $153 \mathrm{~mm}$ w.e. $\mathrm{a}^{-1}$ for the period $1958-2002$, which agrees within $5 \%$ with the latest measurement compilations. Sublimation and melt remove $7 \%$ and $<1 \%$ respectively of the solid precipitation. We found significant seasonality of solid precipitation, with a maximum in autumn and a minimum in summer. No meaningful trend was identified for the SSMB, because the time series of solid precipitation and SSMB are affected by an inhomogeneity in 1980 within the ERA-40 fields that drive RACMO2/ANT. Sublimation, melt and liquid precipitation increase in time, which is related to a modeled increase in $2 \mathrm{~m}$ temperature.
\end{abstract}

\section{INTRODUCTION}

In recent decades, compilations of the surface mass balance of the Antarctic ice sheet have improved in quality (Vaughan and others, 1999; Giovinetto and Zwally, 2000), but they are still compromised by data sparsity (Genthon and Krinner, 2001). At the same time, the quality of global atmospheric models has improved significantly: horizontal and vertical resolution have increased because of increased computer power, and parameterizations of physical processes like precipitation, turbulent and radiative budgets produce more accurate results. Another advance has been the assimilation of measurements into the models. The European Centre for Medium-Range Weather Forecasts (ECMWF) recently completed a 40 year re-analysis project (ERA-40), in which all these improvements are cumulated. ERA-40 aims to give the best and most consistent analysis possible of the global weather during the period September 1957-August 2002.

Over Antarctica, ERA-40 nevertheless shows biases (Genthon, 2002; Reijmer and others, 2005). The surface temperature is overestimated by typically $3 \mathrm{~K}$, mainly because snow albedo is too low. Katabatic winds over the ice-sheet slopes are underestimated because of limited model resolution $(\approx 120 \mathrm{~km})$ resulting in flattened model topography and too high effective surface roughness lengths. Finally, ERA-40 underestimates accumulation in the interior of Antarctica, a common problem with numerical models (Genthon and Krinner, 2001; Van Lipzig and others, 2002).

Compared to a global climate model, a regional atmospheric climate model, forced at the lateral boundaries with output from a general circulation model (GCM) or a reanalysis, is expected to generate a better climatology for
Antarctica, primarily because much higher resolutions are feasible and parameterizations can be adapted to the specific Antarctic situation. The added value of such an approach was shown by, for example, Van Lipzig and Van den Broeke (2002) and Van den Broeke and Van Lipzig (2003), who presented results of a regional atmospheric climate model, run over Antarctica (RACMO1/ANT). This run used the 15 year re-analysis data of ERA-15 as lateral boundary forcing.

Here, we present results of an integration with a new model (RACMO2/ANT), which was driven at the lateral boundaries by output from ERA-40, with a focus on the surface mass balance. The specific, i.e. valid for one location and a certain time period, surface mass balance (SSMB) is defined as the sum of all mass fluxes towards the surface, integrated over a year:

$$
\mathrm{SSMB}=\int_{\text {year }} \mathrm{d} t\left(P_{\mathrm{s}}+\mathrm{SU}+\mathrm{M}+\mathrm{ER}_{\mathrm{ds}}+\mathrm{SU}_{\mathrm{ds}}\right),
$$

where $P_{\mathrm{S}}$ is solid precipitation, $\mathrm{SU}$ is sublimation, $M$ is melt, $E R_{d s}$ is erosion as a result of divergence in the horizontal snowdrift transport, and $\mathrm{SU}_{\mathrm{ds}}$ is sublimation of drifting-snow particles. All values are expressed in mmw.e. $\mathrm{a}^{-1}$, and contributions are positive when directed towards the surface. Note that $\mathrm{SU}, \mathrm{M}, \mathrm{ER}_{\mathrm{ds}}$ and $\mathrm{SU}_{\mathrm{ds}}$ have negative values in Equation (1), because they remove mass from the surface. Snowdrift processes are not included in RACMO2/ ANT, so $E R_{d s}$ and $S U_{d s}$ are not considered in this study. In Antarctica, most (melt)water will refreeze at some depth in the snowpack, where temperatures are still below freezing. As this process ('internal accumulation') is not incorporated in RACMO2/ANT physics, it is not considered further either. 


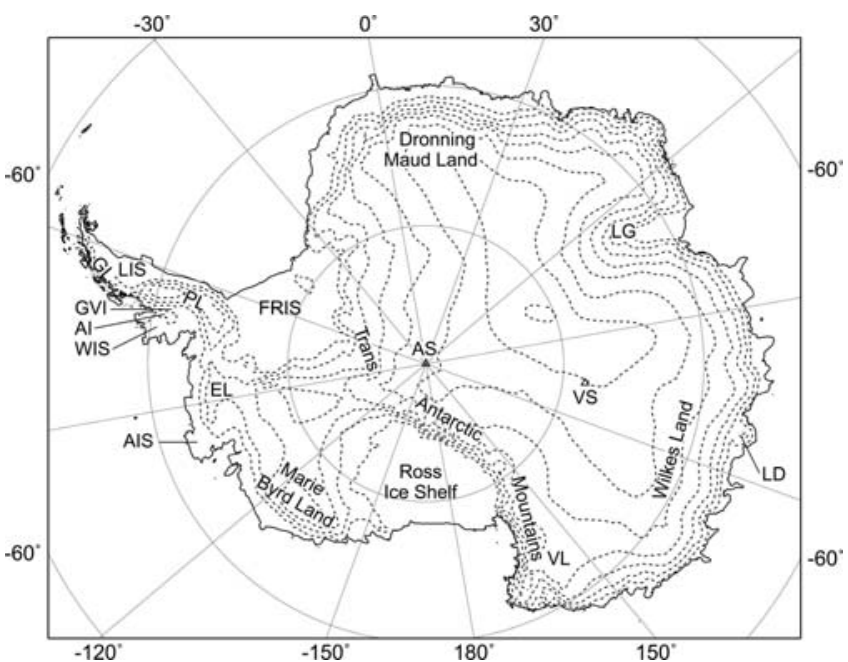

Fig. 1. Map of Antarctica with elevation contours at $500 \mathrm{~m}$ intervals. Locations marked are the Larsen Ice Shelf (LIS), Palmer Land (PL), Graham Land (GL), George VI Ice Shelf (GVI), Alexander Island (AI), Wilkins Ice Shelf (WIS), Filchner-Ronne Ice Shelf (FRIS), Ellsworth Land (EL), Abbot Ice Shelf (AIS), Lambert Glacier (LG), Law Dome (LD), Victoria Land (VL), Amundsen-Scott Station (AS) and Vostok station (VS).

After a short model description in section 2, we present results in section 3, starting with the spatial distribution of the annual mean surface mass-balance components: solid precipitation, sublimation and melt. The modeled SSMB is compared with a compilation of measurements by Vaughan and others (1999). Next, we discuss the seasonality of the various SSMB components, averaged for the grounded ice sheet. Also in section 3, time series of ice-sheet integrated SSMB are compared with those derived from ERA-40. Section 4 discusses some possible shortcomings of the model and observations and a summary is given in section 5 .

\section{MODEL DESCRIPTION}

RACMO2/ANT uses the atmospheric dynamics of the High Resolution Limited Area Model (HIRLAM, version 5.0.6; Undén and others, 2002), which uses a semi-Lagrangian discretization scheme. The description of physical processes is equal to that of the ECMWF atmospheric model used in the ERA-40 re-analysis (cycle CY23R4; White, 2001). RACMO2/ANT differs fundamentally from RACMO1/ANT which was used by Van Lipzig and others (2002). RACMO1/ ANT uses the dynamics of an older version of HIRLAM which had an Eulerian discretization scheme and ECHAM4 physics.

The horizontal resolution of RACMO2/ANT is $\sim 55 \mathrm{~km}$. The model has 40 hybrid levels in the vertical, of which the lowest is at $\sim 10 \mathrm{~m}$ above the surface. Hybrid levels follow the topography close to the surface and pressure levels at higher altitudes. ERA-40 fields force the model at the lateral boundaries, while the interior of the domain is allowed to evolve freely. The model integration over 2002 is completed using ECMWF operational analysis. Sea surface temperature is prescribed from ERA-40; sea ice is determined using sea surface temperature. If sea ice is prescribed, a sea-ice thickness of $1.5 \mathrm{~m}$ is assumed. The model treats ice shelves as grounded ice. Reijmer and others (2005) present a more detailed description of RACMO2/ANT and the associated improvements compared to ERA-40. Below, we restrict ourselves to a summary of the most important model adjustments that were made to better represent Antarctic conditions, and the post-process correction applied to the liquid and solid precipitation.

\subsection{Snow albedo}

The ECMWF description of snow albedo uses the method described by Douville and others (1995), in which the snow albedo decreases linearly from 0.85 , immediately after an accumulation event, to 0.75 in 12.5 days for temperatures below freezing. The method underestimates snow albedo in Antarctica, where temperatures are well below zero and the albedo changes very slowly.

The snow albedo scheme of Van den Hurk and Viterbo (2003) was therefore implemented in RACMO2/ANT. This method accounts for the temperature effect on albedo changes and assumes a negligible decrease of albedo when temperatures are below $-10^{\circ} \mathrm{C}$. Furthermore, we increased the lower limit of albedo to 0.80 and lowered the threshold value of a snow event affecting the albedo to $0.3 \mathrm{~mm} \mathrm{~h}^{-1}$. In the original formulation, the sea-ice albedo consisted of a climatological value with a fixed seasonal cycle. In the formulation of RACMO2/ANT, the sea-ice albedo was calculated using the snow albedo scheme, but the minimum sea-ice albedo was set to 0.6 .

\subsection{Surface roughness lengths}

The surface roughness length for momentum $\left(z_{0}\right)$ was initially calculated with the method described by White (2001). This method, however, leads to an overestimation of the roughness length in Antarctica, with values up to $100 \mathrm{~m}$. Therefore, $z_{0}$ was scaled down to a basic value of $10^{-3} \mathrm{~m}$ for the ice sheet and allowed to increase to up to $1 \mathrm{~m}$ for mountainous areas like the Transantarctic Mountains, to account for subgrid orography. The ECMWF physics uses the method of White (2001) for the calculation of the roughness lengths for heat and moisture $\left(z_{h}, z_{q}\right)$. We replaced this by Andreas' (1987) theoretical model, which was developed especially for snow and ice surfaces. The model expresses $z_{\mathrm{h}}$ as a function of $z_{0}$ and the surface friction velocity $u_{*}$. Typical new values of $z_{\mathrm{h}}$ are $3 \times 10^{-4} \mathrm{~m}$ for the quiet upper parts of the interior, decreasing to $6 \times 10^{-6} \mathrm{~m}$ for the mountain regions. We assume $z_{q}$ to be equal to $z_{\mathrm{h}}$.

\subsection{Snow model}

The original ECMWF physics treats the surface of the ice sheets as a seasonal snow cover, i.e. as a single snow layer of $10 \mathrm{~m}$ w.e. thickness on top of soil, while all calculations of snow temperature use a snow layer of $1 \mathrm{~m}$ w.e. thickness. An infinitely thin skin layer is used to derive surface energy fluxes and surface temperature.

In RACMO2/ANT, a four-layer snow model was added between the snow layer already present and the soil. The thickness of the snow layers is fixed and increases with depth from $0.1 \mathrm{~m}$ to $6 \mathrm{~m}$. Daily and seasonal variations of snow temperature are better represented with this model. The representation of melt and runoff was not changed. Meltwater is assumed to run off immediately, and not to refreeze in the deeper snow layers. Due to the low temperatures in Antarctica, melt seldom occurs in the interior, but occurs quite frequently in the coastal zone (Schneider and Steig, 2002). 


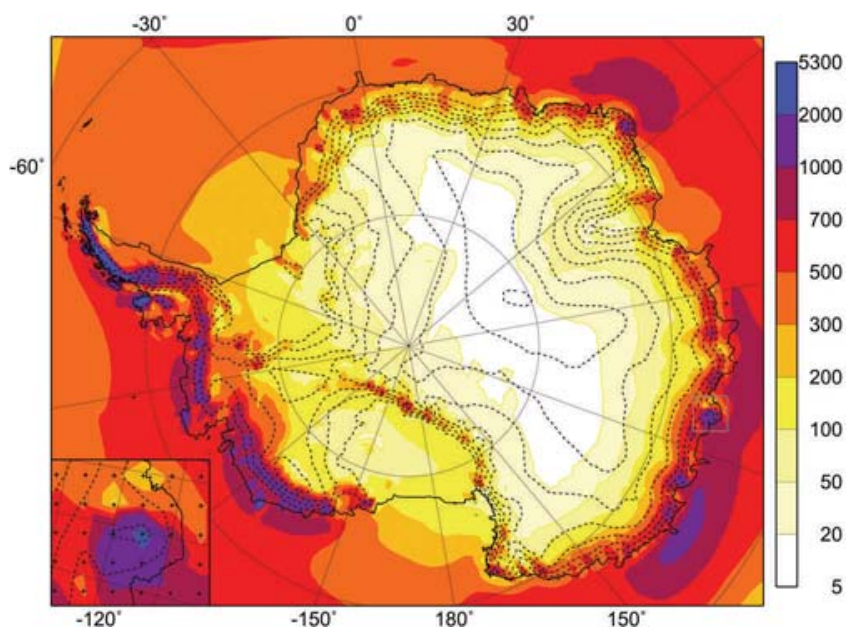

Fig. 2. Modeled annual solid precipitation $\left(P_{\mathrm{s}}\right)$ averaged for the period 1958-2002. The inset shows an enlargement of the pattern over Law Dome (grey square). Crosses in this inset mark the location of the model gridpoints. Units are $\mathrm{mm}$ w.e. $\mathrm{a}^{-1}$.

\subsection{Correction of the liquid and solid precipitation}

It was found that RACMO2/ANT overestimates the liquid precipitation over Antarctica at the expense of solid precipitation, because of an inadequate parameterization of precipitation formation in mixed-phase clouds at temperatures between -20 and $0^{\circ} \mathrm{C}$. In this temperature range, the parameterization utilized in the ECMWF physics (White, 2001) assumes a direct conversion of cloud water and cloud ice into liquid and solid precipitation, respectively. However, if cloud ice exists at the level where precipitation is formed, the precipitation will develop as solid only (Rogers and Yau, 1989). We have corrected the liquid and solid precipitation output of RACMO2/ANT by analyzing the daily vertical profiles of temperature and precipitative fluxes, assuming that the precipitation develops as solid if the vertical layers, in which the precipitation is formed, are partly colder than $-10^{\circ} \mathrm{C}$, leaving the total precipitation sum unchanged. More detail about this correction will be given in a forthcoming paper.

\section{RESULTS}

In this section, we discuss the spatial and temporal variability of the modeled SSMB components over Antarctica. Figure 1 shows a map of Antarctic topography and the topographical features mentioned in the text.

\subsection{Solid precipitation}

Figure 2 shows the corrected annual mean solid precipitation $\left(P_{\mathrm{s}}\right)$, averaged for 1958-2002. The Antarctic interior is dry, and the coastal slopes, in particular of Marie Byrd Land and the Antarctic Peninsula, receive most precipitation. Note the very strong upwind/downwind effects on $P_{\mathrm{s}}$ in coastal East Antarctica, where topographic promontories block the circumpolar easterlies. The spatial pattern of $P_{\mathrm{s}}$ over Law Dome is shown as an example in the inset. The model grid (the crosses in the inset of Fig. 2) greatly simplifies the $P_{\mathrm{s}}$ pattern over Law Dome. Nevertheless, the modeled upwind/downwind effect is a realistic phenomenon, considering the observed strong east-west accumulation gradients on Law Dome (Van Ommen and others, 2004).

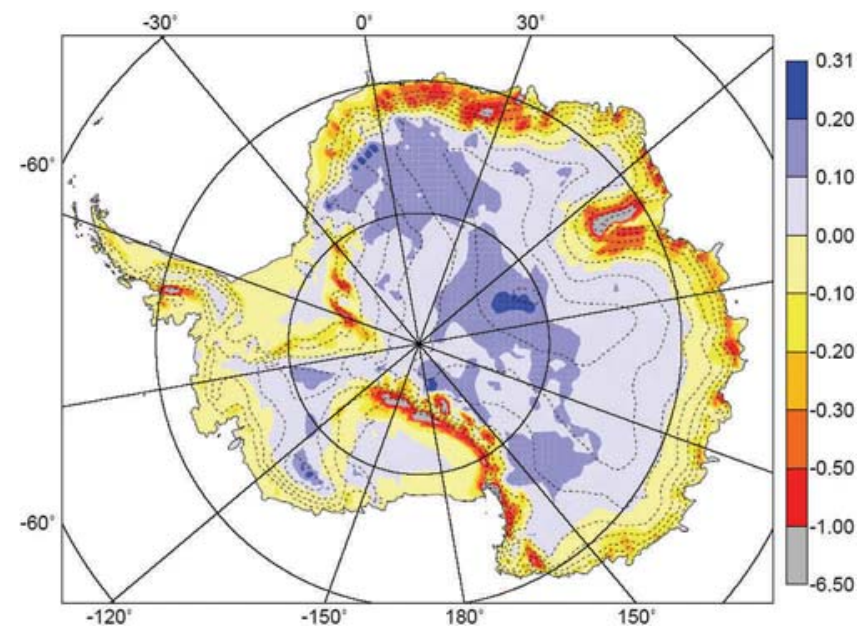

Fig. 3. Modeled sublimation/deposition, expressed as a fraction of the solid precipitation, i.e. SU/P $P_{\mathrm{s}}$ averaged for the period 1958 2002. Values below -1 (grey areas) indicate that sublimation exceeds precipitation.

Strong precipitation shadow effects are also visible east of the Antarctic Peninsula and over the Ross Ice Shelf.

After the correction described in section 2.4, the frequency of rain events (not shown) agrees with the sparse information available (Turner and others, 1995; King and Turner, 1997). Only the coasts receive some rain, but less than $10 \mathrm{~mm} \mathrm{a}^{-1}$ except for the Antarctic Peninsula. Towards the northern edge of the Antarctic Peninsula, the amount of rain quickly increases to $100 \mathrm{~mm} \mathrm{a}^{-1}$, which is still a small amount compared to the solid precipitation (Fig. 2).

\subsection{Sublimation}

Sublimation is largely controlled by temperature, which depends strongly on elevation, and regionally by the katabatic wind. The largest values of absolute net sublimation (not shown) are found in Dronning Maud Land and the Transantarctic Mountains, with values up to $200 \mathrm{~mm}$ w.e. $\mathrm{a}^{-1}$. Net deposition is largest on the West Antarctica plateau, where it reaches values up to $25 \mathrm{~mm}$ w.e. $\mathrm{a}^{-1}$. The sublimation on the slopes of Antarctica is similar to earlier model-based estimates (Van den Broeke, 1997, and references therein), but the interior deposition seems to be slightly overestimated locally when compared to calculations based on automatic weather station (AWS) observations (Van den Broeke and others, 2005).

The sublimation as a fraction of the solid precipitation $\left(\mathrm{SU} / P_{\mathrm{S}}\right)$ is shown in Figure 3. The areas where sublimation exceeds solid precipitation, in Dronning Maud Land, the Lambert Glacier valley and at the foot of the Transantarctic Mountains, are drawn grey. These areas could be sensitive to blue-ice formation (see section 3.4). Over large parts of the dry East Antarctic plateau, deposition constitutes about 10\% of the amount of solid precipitation, although the absolute amount is $<3 \mathrm{~mm}$ w.e. $\mathrm{a}^{-1}$.

\subsection{Melt}

Annual surface melt is shown as a fraction of the solid precipitation in Figure 4. As can be seen, all ice shelves experience melting. Large melt fractions of $>50 \%$ are found on the western side of the Antarctic Peninsula (the Wilkins and George VI Ice Shelves), and up to $25 \%$ on the Abbot Ice 


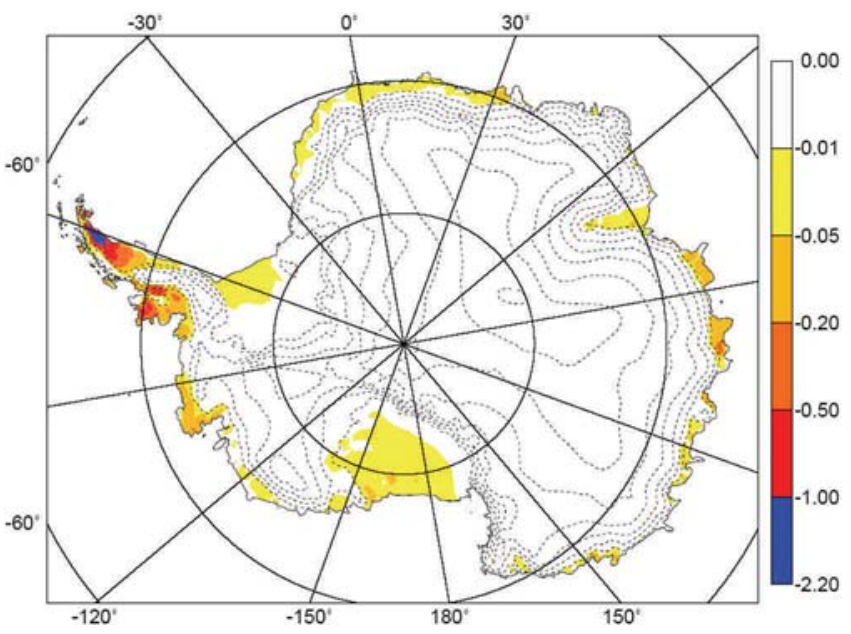

Fig. 4. Annual melt flux, expressed as fraction of the solid precipitation $\left(M / P_{\mathrm{s}}\right)$, averaged for the period 1958-2002. When this value is less than -1 (blue areas), more snow is removed by melt than is added by snowfall.

Shelf, West Antarctica. Melt exceeds solid precipitation on the former Larsen A and B ice shelves on the eastern side of the Antarctic Peninsula. The absolute annual melt flux (not shown) reaches a maximum of $0.5 \mathrm{~m}$ w.e. $\mathrm{a}^{-1}$ at the northern edge of the Larsen Ice Shelf. The value for this location is probably an underestimation, since the lower limit of the albedo was set at 0.8. A much lower albedo is likely for large melt events. For example, meltwater ponds have been observed over the Larsen A and B ice shelves and Wilkins Ice Shelf during summer months (Scambos and others, 2000), and melt ponds significantly reduce the surface albedo. The modeled strong melt cannot be compared to observations since the surface mass balance has not been measured on the northern part of the Larsen Ice Shelf. The largest melt is nevertheless expected at sea level on the western side of the Antarctic Peninsula, where temperatures are significantly higher than on the eastern side. However, at the employed resolution of $55 \mathrm{~km}$ the model does not contain continental gridpoints with an elevation $<200 \mathrm{~m}$ in this area, so this maximum is not well represented.

\subsection{Specific surface mass balance (SSMB)}

Figure 5 a shows the SSMB, i.e. the sum of solid precipitation, sublimation/deposition and melt, as modeled in RACMO2/ANT. As expected, the SSMB largely reflects the distribution of solid precipitation (Fig. 2), but sublimation and melt do have important regional impacts. For instance, sublimation removes an important part of the precipitated snow in Dronning Maud Land, over the Lambert Glacier basin and at the foot of the Transantarctic Mountains, leading locally to areas with a negative SSMB (grey areas in Fig. 5a). Note that a negative SSMB only occurs in areas with high sublimation together with low solid precipitation.

For comparison, the absolute differences between the modeled SSMB and the SSMB compilation of Vaughan and others (1999), based on in situ measurements, are shown in Figure 5b. Although many deviations are visible, overall the two fields are in good qualitative agreement. Areas with known higher accumulation compared to other coastal zones, i.e. the western part of the Antarctic Peninsula and Ellsworth Land, also have higher accumulation in the
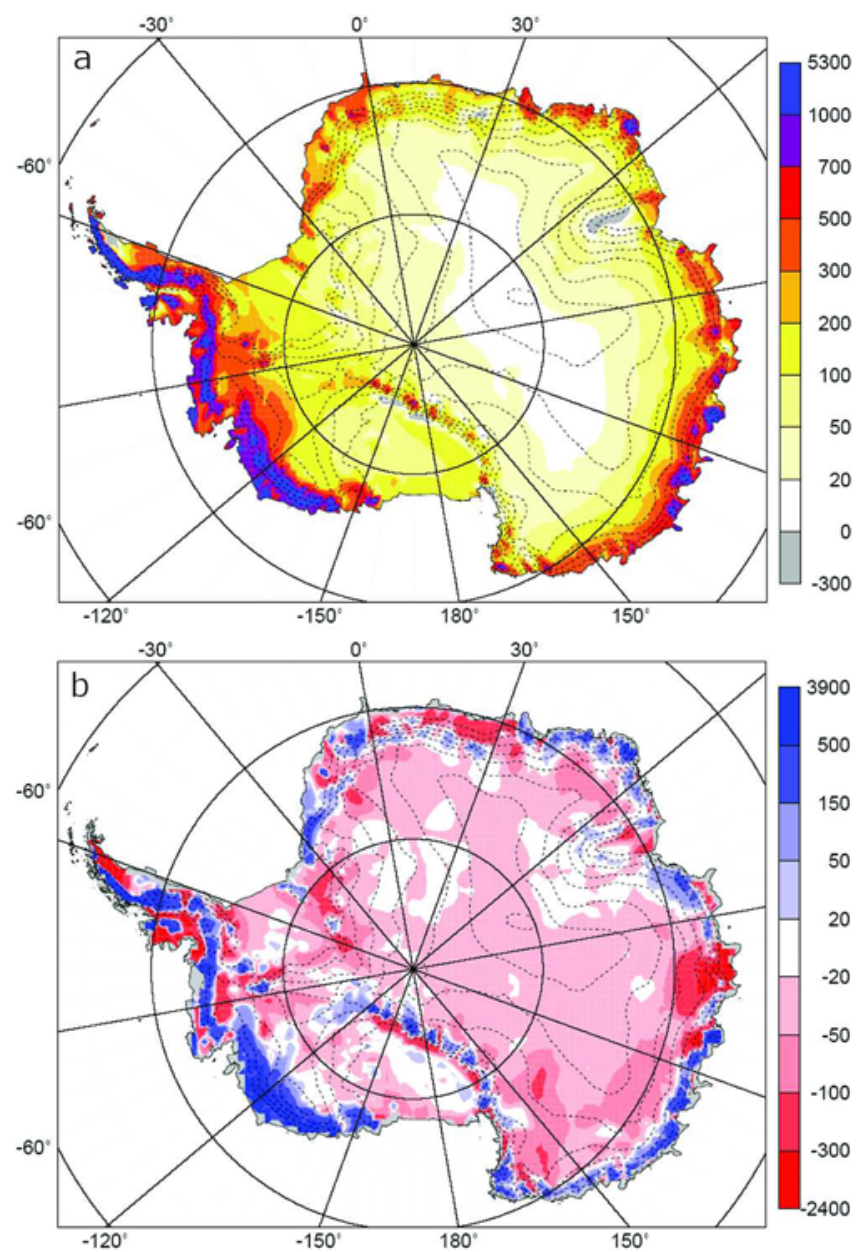

Fig. 5. (a) Modeled SSMB ( $m$ mw.e. $\mathrm{a}^{-1}$ ), averaged for the period 1958-2002. (b) Difference map with the compilation of the surface mass balance ( $\mathrm{mm} \mathrm{w.e.} \mathrm{a}^{-1}$ ), based on in situ observations (Vaughan and others, 1999). Positive values imply that the modeled SSMB exceeds the compilation. Gridpoints for which the compilation is not determined are drawn grey.

modeled SSMB. The extent of the dry interior, where accumulation is typically $<100 \mathrm{~mm}$, is reproduced well. Areas with a negative SSMB in RACMO2/ANT compare well in distribution and extent with reported blue-ice areas (Winther and others, 2001), though RACMO2/ANT predicts blue-ice areas in Dronning Maud Land and at the foot of the Transantarctic Mountains at somewhat lower elevations than reported.

However, systematic differences are also noticed. The SSMB in the interior in the Vaughan and others (1999) compilation exceeds the modeled SSMB by about $30 \mathrm{~mm} \mathrm{a}^{-1}$, about a factor of 2. Modeled SSMBs over the coastal slopes are systematically greater than those reported by Vaughan and others (1999). Especially remarkable is the large modeled SSMB on the Marie Byrd Land coast, which is much greater than compiled values in Figure $5 \mathrm{~b}$.

The resemblance between modeled and observed SSMB in the Antarctic Peninsula (as compiled by Turner and others, 2002; not shown) is very strong. The spatial pattern and absolute values agree. The negative SSMB modeled on the Larsen and Wilkins Ice Shelves is caused by a combination of low solid precipitation (Fig. 2), due to the rain-shadow effect of the Antarctic Peninsula for the Larsen Ice Shelf and of Alexander Island for the Wilkins Ice Shelf, and large 


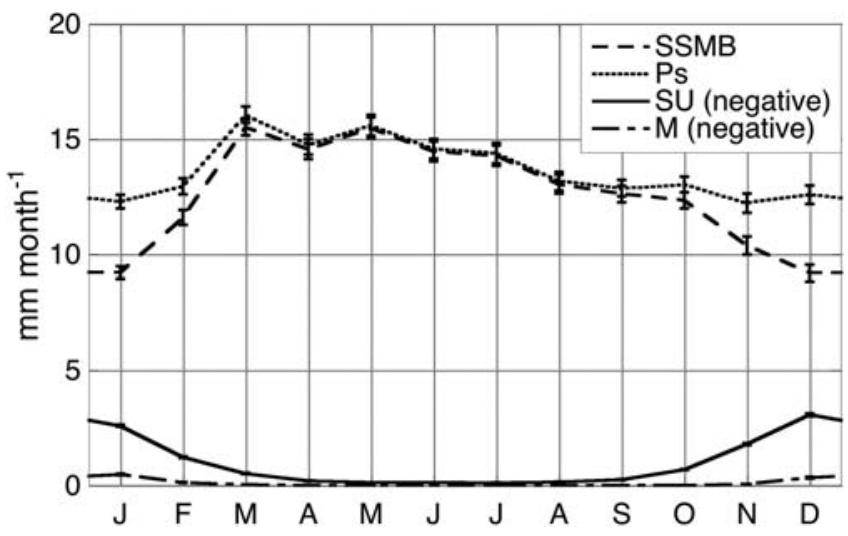

Fig. 6. Modeled seasonality of the SSMB and its components over the grounded ice sheet (1958-2002). $P_{\mathrm{s}}$ SU and $M$ denote solid precipitation, sublimation and melt, respectively. Error bars denote the uncertainty due to year-to-year variability.

melting values (Fig. 4). It is well known that ice shelves in these regions have shown significant retreat in recent decades, which has so far been primarily ascribed to an increase in melt (Vaughan and Doake, 1996; Scambos and others, 2000).

The SSMB as modeled by RACMO2/ANT is better in several respects than the results of RACMO1/ANT (Van Lipzig and others, 2002, fig. 6b). The spatial resolution has increased, because smoothing of the model fields is no longer required due to the improved discretization scheme. Sublimation has decreased to more realistic values, due to improved estimates of the surface roughness lengths, and melt has been added. However, underestimation of the SSMB over the interior has increased, and much higher SSMBs are modeled in the coastal zone, which is not necessarily an improvement.

Using the grounding-line definitions of Vaughan and others (1999), 45 year means of modeled solid precipitation, sublimation, melt and rain, averaged over the grounded ice sheet, are $164,-11,-1$ and $<1 \mathrm{~mm}$ w.e. $\mathrm{a}^{-1}$, respectively. The modeled SSMB over the grounded ice sheet is $153 \mathrm{~mm}$ w.e. $\mathrm{a}^{-1}$. When the ice shelves and ice rises are included, the SSMB increases to $165 \mathrm{~mm}$ w.e. $\mathrm{a}^{-1}$. When all meltwater and liquid precipitation is added, the values increase by 1.5 and $4 \mathrm{~mm}$ w.e. $\mathrm{a}^{-1}$, respectively.

Table 1 shows that the modeled SSMB, averaged over 1958-2002, compares well with estimates based on measurements by Vaughan and others (1999) and Giovinetto and Zwally (2000). The modeled SSMB for the satellite era only, beginning in 1980, is somewhat higher than the latter estimates. The RACMO2/ANT modeled SSMB also compares well with model results of Krinner and others (1997) and Van Lipzig and others (2002), but note the different time periods. The model results of Bromwich and others (2004) are slightly higher (Table 1 ).

\subsection{Seasonality of the mass balance}

Figure 6 shows the modeled seasonality (1958-2002 average) of the various SSMB components. All components of the SSMB show a seasonality that exceeds the uncertainty due to year-to-year variability. Solid precipitation $\left(P_{\mathrm{s}}\right)$ is smallest during summer, and peaks in autumn. A similar pattern was found by Van Lipzig and others (2002), but in that study the amplitude was not significant, as a result of the

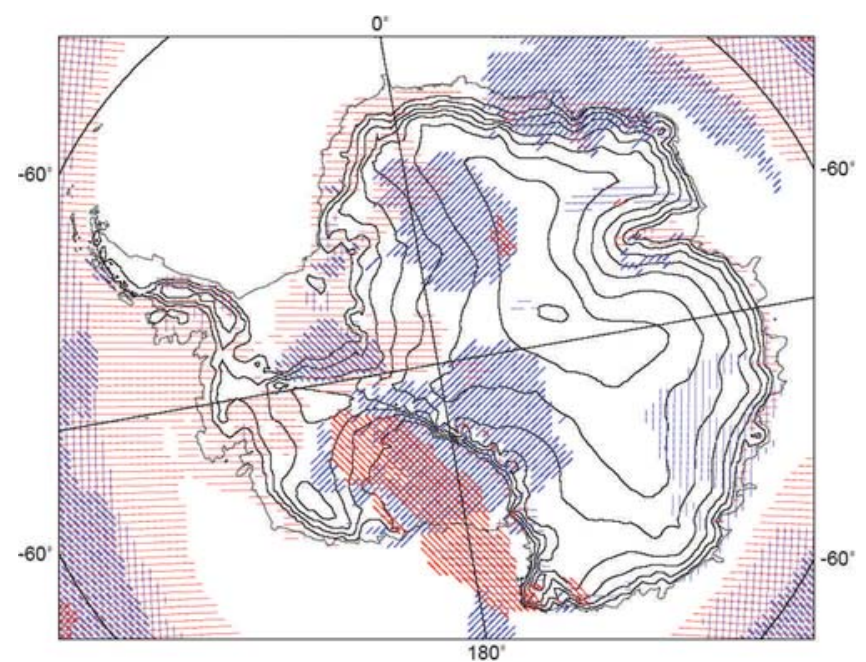

Fig. 7. Seasonality of solid precipitation (1958-2002). Blue lines mark areas in which a season is $33 \%$ wetter than the annual mean; red lines mark 33\% dryer than the annual mean. Deviations were derived by comparing mean daily solid precipitation. Hatching denotes seasons as follows: —: summer; /: autumn; |: winter; $\backslash$ : spring.

shorter period. Sublimation (SU) and melt (M) peak during summer and nearly vanish in the other months. In the summer months December and January, sublimation becomes a significant sink term in the SSMB, removing 25$30 \%$ of the solid precipitation from the surface. Averaged over the year and across the grounded ice sheet, sublimation removes $7 \%$ of solid precipitation. This is less than Van den Broeke's (1997) GCM-based estimate of 10-15\%, but compares well with sublimation calculations from AWSs (Van den Broeke and others, 2005).

Figure 7 shows the seasonality of the solid precipitation per region. The solid precipitation is shown, instead of the $\mathrm{SSMB}$, to avoid a bias associated with sublimation and melt, both summer phenomena. The Filchner-Ronne Ice Shelf and large coastal areas have dry summers (horizontal red lines).

Table 1. Integrated SSMB (mm w.e. $\mathrm{a}^{-1}$ ) from RACMO2/ANT compared to several compilations

\begin{tabular}{|c|c|c|c|c|}
\hline & \multirow[t]{2}{*}{ Period } & \multicolumn{3}{|c|}{ SSMB } \\
\hline & & $\begin{array}{c}\text { Grounded } \\
\text { ice sheet }\end{array}$ & Antarctica & Antarctica* \\
\hline RACMO2/ANT & 1958-2002 & 153 & 165 & 154 \\
\hline RACMO2/ANT & 1958-79 & 139 & 152 & 141 \\
\hline RACMO2/ANT & 1980-2002 & 166 & 178 & 166 \\
\hline $\begin{array}{l}\text { Vaughan and } \\
\text { others (1999) }\end{array}$ & Variable & 149 & 166 & \\
\hline $\begin{array}{l}\text { Giovinetto and } \\
\text { Zwally (2000) }\end{array}$ & Variable & & & $149 \pm 14$ \\
\hline $\begin{array}{l}\text { Van Lipzig and } \\
\text { others (2002) }\end{array}$ & 1979-93 & 156 & & \\
\hline $\begin{array}{l}\text { Krinner and } \\
\text { others (1997) }\end{array}$ & 5 years & & 162 & \\
\hline $\begin{array}{l}\text { Bromwich and } \\
\text { others (2004) }\end{array}$ & $\begin{array}{l}\text { July } 1996- \\
\text { June } 1999\end{array}$ & & $186 \pm 16$ & \\
\hline
\end{tabular}

*Except Graham Land, the former Larsen Ice Shelf and eastern Palmer Land. 


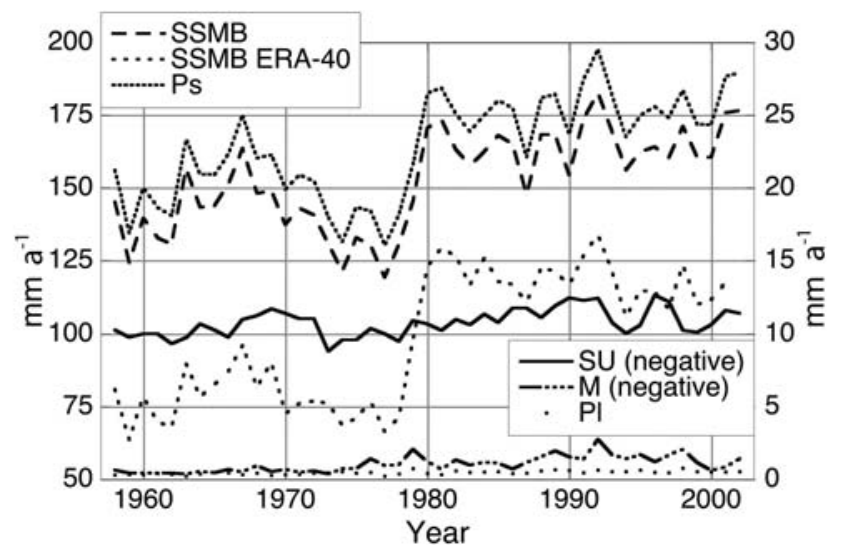

Fig. 8. Time series of the SSMB components, averaged for the grounded ice sheet as found by RACMO2/ANT. The left axis displays the values of SSMB, the SSMB determined by ERA-40 and solid precipitation $\left(P_{\mathrm{S}}\right)$; the right axis the values for the sublimation (SU) and melt $(M)$

Solid precipitation is largest during autumn over large parts of Antarctica. Wilkes Land, however, receives most solid precipitation during winter. This figure compares well with the results of Genthon and others (1998) and Van Lipzig and others (2002). The solid-precipitation minima and maxima over the ocean are a result of the seasonal cycle of temperature and the associated solid fraction of the precipitation, i.e. less snowfall in summer and more in winter.

\subsection{Interannual variability and trends}

Figure 8 shows year-to-year variations in the various terms of the SSMB integrated over the grounded ice sheet. We also included the SSMB of ERA-40, calculated by including rain and neglecting melt. We had to do so to obtain realistic values, because in ERA-40 rain is strongly overestimated and melt is unrealistically large probably due to underestimated snow albedo. In an absolute sense, all components show an increase in time (Table 2). Nevertheless, the time series of solid precipitation and SSMB show an inhomogeneity around 1980, which is most pronounced in the ERA-40 SSMB. For all time series, the method of Easterling and Peterson (1995) was used to trace inhomogeneities. Linear trends in the solid precipitation and SSMB over the split periods (pre- and post-1980) are not significant.

The time series of sublimation, melt and rain $\left(P_{1}\right)$ do not show an inhomogeneity around 1980 . Sublimation, melt and liquid precipitation are controlled most by near-surface meteorological conditions, unlike solid precipitation, which is strongly dependent on the large-scale circulation. Nearsurface conditions are less sensitive to changes in general circulation forcing from ERA-40 at the lateral boundaries than the large-scale circulation itself. Therefore, an absence of an inhomogeneity is possible. Linear trend fits to the data are summarized in Table 2. The trends in sublimation, melt and liquid precipitation for the period 1958-2002 are much larger than the uncertainty due to interannual variability. Note, however, that $2 \mathrm{~m}$ temperature trends are overestimated in RACMO2/ANT. Trend analysis on the split periods gives similar values, except for the sublimation. Sublimation seems to be affected by multi-annual variations, which erase the possible trend if the split time series are considered.

Figure 8 shows that the solid precipitation varies strongly from year to year. The regional variability (not shown) is even larger. The standard deviation of $P_{\mathrm{s}}$ reaches up to $50 \%$ of the annual sum in Victoria Land, Lambert Glacier, the inland part of Marie Byrd Land and the southern and eastern parts of the Filchner-Ronne Ice Shelf.

\section{DISCUSSION}

\subsection{Spatial distribution of measured and modeled SSMB}

Compared with a recent compilation of Antarctic SSMB, RACMO2/ANT appears to underestimate accumulation on the plateau of East and West Antarctica and to overestimate accumulation on the steep coastal slopes. For instance, modeled accumulation on the slopes of Marie Byrd Land is twice the values presented by Vaughan and others (1999).

The high modeled accumulation over the ice-sheet slopes may have been caused by artificial diffusion of moisture along model levels. This diffusion, implemented to stabilize the model, generates an artificial uphill moisture transport. Diffusion-enhanced moisture transport is a common problem with atmospheric models in regions of steep topography (see Connolley and King, 1996; Van Lipzig and Van den Broeke, 2002; Lenderink and others, 2003). A 1 month test with the horizontal diffusion of moisture switched off shows an accumulation reduction of about $10 \%$ on the steepest slopes (not shown). This modest change casts doubt on the assumption that horizontal diffusion is the culprit.

Other reasons for the differences between modeled and compiled SSMB could be snowdrift transport and snowdrift sublimation, which are not included in RACMO2/ANT. Snowdrift sublimation and erosion is strongest in areas with the strongest wind, which is closely related to the topographic slope. RACMO2/ANT especially seems to overestimate solid precipitation in regions with a large surface slope; therefore including snowdrift-associated processes might bring the model results closer to the observations.

The modeled SSMB is more than twice that presented by Vaughan and others (1999) on the slopes of Marie Byrd Land, but compares well with results of other models in this region (e.g. RACMO/ANT1 (Van Lipzig and others, 2002), other GCMs and ERA-15 (Genthon and Krinner, 2001)). Such a common bias may be caused by neglecting snowdrift, but it is difficult to explain why snowdrift would strongly affect the accumulation on the slopes of Marie Byrd Land only. Therefore, the sparsity of measurements in this region could also be partly responsible for the difference.

The underestimation of SSMB on the Antarctic Plateau appears to be a shortcoming of many numerical atmospheric models (see Genthon and Krinner, 2001; Van Lipzig and others, 2002). One reason could be the neglect of diamond dust, the physical mechanism of which is yet not fully understood. Diamond dust can constitute a substantial component of the SSMB in the Antarctic interior (e.g. up to $75 \%$ at Vostok (Ekaykin, 2003)). The artificial diffusion of moisture is not the source for the possible underestimation of the SSMB in the interior. The test without horizontal diffusion showed no significant increase of SSMB in this part of Antarctica.

The sparsity and temporal inhomogeneity of accumulation measurements could also partly explain the differences. The reliability of observation compilations depends strongly on the quality of the interpolation, in particular over the coastal slopes where accumulation gradients are large. Furthermore, the observations have not been corrected to 
Table 2. Results of linear trend analysis of SSMB components averaged over the grounded ice sheet. The method described by Easterling and Peterson (1995) was used to determine the position of the inhomogeneity in the $P_{\mathrm{s}}$ time series. Mean values are in mm w.e. $\mathrm{a}^{-1}$ and trends in mm w.e. $\mathrm{a}^{-2}$. Error margins in trends are one standard deviation

\begin{tabular}{|c|c|c|c|c|c|c|}
\hline & \multicolumn{2}{|c|}{ 1958-2002 } & \multicolumn{2}{|c|}{ 1958-79 } & \multicolumn{2}{|c|}{ 1980-2002 } \\
\hline & Mean & Trend & Mean & Trend & Mean & Trend \\
\hline \multicolumn{7}{|c|}{ RACMO2/ANT } \\
\hline SSMB & 153 & - & 139 & $-0.49 \pm 0.40$ & 166 & $0.15 \pm 0.28$ \\
\hline$P_{\mathrm{s}}$ & 164 & - & 150 & $-0.45 \pm 0.39$ & 178 & $0.17 \pm 0.27$ \\
\hline SU & -10.8 & $-0.035 \pm 0.010$ & -10.3 & $-0.007 \pm 0.03$ & -11.3 & $-0.009 \pm 0.03$ \\
\hline$M$ & -1.0 & $-0.029 \pm 0.005$ & -0.7 & $-0.04 \pm 0.010$ & -1.4 & $-0.013 \pm 0.15$ \\
\hline \multirow[t]{3}{*}{$P_{1}$} & 0.5 & $0.006 \pm 0.001$ & 0.4 & $0.007 \pm 0.004$ & 0.5 & $0.005 \pm 0.004$ \\
\hline & \multicolumn{2}{|c|}{ 1958-2001 } & \multicolumn{2}{|c|}{ 1958-79 } & \multicolumn{2}{|c|}{ 1980-2001 } \\
\hline & Mean & Trend & Mean & Trend & Mean & Trend \\
\hline \multicolumn{7}{|c|}{$E R A-40$} \\
\hline$P$ & 120 & - & 97 & $0.18 \pm 0.34$ & 142 & $-0.42 \pm 0.24$ \\
\hline
\end{tabular}

cover a common time period. A detailed evaluation of the differences between measured and modeled SSMB will be made in a forthcoming paper.

\subsection{The integrated SSMB}

The problems listed above also affect the integrated SSMB values, but because they partly compensate, the differences between integrated values are small (Table 1). The divergence in wind-driven transport of snow is assumed to be an order of magnitude or more smaller than the other moisture fluxes in the Antarctic SSMB (Déry and Yau, 2002). The contribution of diamond dust to the SSMB is probably significant in the very dry interior, but decreases when the integrated SSMB is considered. Refreezing of liquid precipitation adds an uncertainty of only $1 \mathrm{~mm}$ w.e. $\mathrm{a}^{-1}$. The long integration period reduces the uncertainty in the mean SSMB due to year-to-year variability to $\sim 3 \mathrm{~mm}$ w.e. $\mathrm{a}^{-1}$. Finally, the temporal inhomogeneity in the SSMB adds uncertainty to the time-integrated sums. Since ERA-40 might be of lesser quality before 1980, the inhomogeneity observed for 1980 might indicate that the modeled SSMB before 1980 is slightly underestimated. Despite these uncertainties, the integrated SSMB compares well with measurement estimates.

\subsection{Interannual variability and trends}

Contrary to what was argued by Bromwich (1988), we found a relatively large year-to-year variation of the Antarctic SSMB. A significant inhomogeneity was found in the time series of solid precipitation and SSMB of RACMO2/ANT, which is even larger in ERA-40. This inhomogeneity nearly coincides with the start of the data assimilation of modern satellite measurements (e.g. TIROS Operational Vertical Sounder) into the re-analysis in 1979 (see www.ecmwf.int). The increase in SSMB is probably mainly caused by this inhomogeneity in input data. Any trend analysis of the time series of solid precipitation and SSMB would therefore require an accurate estimate of the magnitude of the SSMB inhomogeneity.

The linear trends of the sublimation (SU) and melt $(M)$ for 1958-2002 in Table 2 are significant up to $99 \%$. We found no indication that these time series were affected by inhomogeneities, but the integrated sublimation correlates well with the averaged $2 \mathrm{~m}$ temperature $(r=0.69$, detrended). A smooth, continent-wide increasing trend in $2 \mathrm{~m}$ temperature is modeled by RACMO2/ANT. The temperature records of Admundsen-Scott and Vostok stations and the satellite observations from 1979 to 1998 (Comiso, 2000) show a cooling trend. The modeled temperature and sublimation trends are likely erroneous. Satellite observations of melt suggest a decreasing trend averaged over Antarctica (Torinesi and others, 2003). A strong increase in rain is observed on the Antarctic Peninsula (Turner and others, 1997). It is too early to draw a final conclusion about uncertainty trends based on model results.

\section{CONCLUSIONS}

We present characteristics of the SSMB of Antarctica, using a regional atmospheric climate model (RACMO2/ANT), driven at the lateral boundaries by ERA-40 data. This model has a favorable combination of high horizontal $(\sim 55 \mathrm{~km})$ and vertical resolution (40 layers) and a long integration period (1958-2002). The modeled Antarctic SSMB, integrated over the grounded ice sheet, agrees well with earlier estimates from models and observations. The modeled spatial SSMB distribution is in good qualitative agreement with the most recent measurement compilations. However, the model seems to underestimate the SSMB in the interior of Antarctica, whereas it overestimates the SSMB on steep coastal slopes. The reasons for this are unclear. The effect of artificial moisture diffusion appears to be small. Other possible reasons are the neglect of snowdrift transport, snowdrift sublimation and diamond dust in RACMO2/ANT. However, the sparsity and temporal mismatch of accumulation observations and shortcomings in the interpolation procedure should not be ruled out.

The integrated solid precipitation peaks in autumn, but the seasonality of the solid precipitation differs regionally. Sublimation and melt are only significant in summer. Where modeled sublimation exceeds solid precipitation, we find blue-ice areas or dry valleys in qualitative agreement with their present position. Melt only affects ice shelves, 
especially the former Larsen A and B ice shelves in the northern Antarctic Peninsula: here, melt exceeds solid precipitation and causes the SSMB to become significantly negative.

The modeled time series of SSMB and solid precipitation are dominated by an inhomogeneity in 1980, which is even more prominent in the ERA-40 record. Given that the inhomogeneity coincides with the start of extensive satellite data assimilation into ERA-40, we suspect that this increase is of numerical origin, rather than a climatological shift. However, sublimation and melt increase significantly within the full time-span of the RACMO2/ANT integration.

In the light of the good quality of this new dataset as described above, we conclude that this dataset offers a range of possibilities not only for the study of the Antarctic SSMB, but also for research of regional climate-change, energybalance and circulation patterns.

\section{ACKNOWLEDGEMENTS}

Thanks to D.G. Vaughan for providing the data of his massbalance compilation, and to ECMWF which made available the ERA-40 fields. We also thank the reviewers for valuable comments which improved the manuscript.

\section{REFERENCES}

Andreas, E.L. 1987. A theory for the scalar roughness and the scalar transfer coefficients over snow and sea ice. Bound-Lay. Meteorol., 38(1-2), 159-184.

Bromwich, D.H. 1988. Snowfall in high southern latitudes. Rev. Geophys., 26(1), 149-168.

Bromwich, D.H., Z. Guo, L. Bai and Q. Chen. 2004. Modelled Antarctic precipitation. Part I: spatial and temporal variability. J. Climate, 17(3), 427-447.

Comiso, J.C. 2000. Variability and trends in Antarctic surface temperatures from in situ and satellite infrared measurements. J. Climate, 13(10), 1674-1696.

Connolley, W.M. and J.C. King. 1996. A modeling and observational study of East Antarctic surface mass balance. J. Geophys. Res., 101(D1), 1335-1344.

Déry, S.J. and M.K. Yau. 2002. Large-scale mass balance effects of blowing snow and surface sublimation. J. Geophys. Res., 107(D23), 4679. (10.1029/2001JD001251.)

Douville, H., J.F. Royer and J.F. Mahfouf. 1995. A new snow parameterization for the Météo-France climate model. Part 1. Validation in stand-alone experiments. Climate Dyn., 12(1), 21-35.

Easterling, D.R. and T.C. Peterson. 1995. A new method for detecting undocumented discontinuities in climatological time series. Int. J. Climatol., 15, 369-377.

Ekaykin, A.A. 2003. Meteorological regime of central Antarctica and its role in the formation of isotope composition of snow thickness. (PhD thesis, Université Joseph Fourier, Grenoble.)

Genthon, C. 2002. Climate and surface mass balance of the polar ice sheets in ERA40/ERA15. Re-Analysis Project Report Series 3. Reading, European Centre for Medium-Range Weather Forecasts.

Genthon, C. and G. Krinner. 2001. The Antarctic surface mass balance and systematic biases in GCMs. J. Geophys. Res., 106(D18), 20,653-20,664.

Genthon, C., G. Krinner and M. Déqué. 1998. Intra-annual variability of Antarctic precipitation from weather forecasts and high-resolution climate models. Ann. Glaciol., 27, 488-494.

Giovinetto, M.B. and H.J. Zwally. 2000. Spatial distribution of net surface accumulation on the Antarctic ice sheet. Ann. Glaciol., 31, 171-178.

King, J.C. and J. Turner. 1997. Antarctic meteorology and climatology. Cambridge, etc., Cambridge University Press.
Krinner, G., C. Genthon, Z.X. Li and P.L. Van. 1997. Studies of the Antarctic climate with a stretched-grid general circulation model. J. Geophys. Res., 102(D12), 13,731-13,745.

Lenderink, G., E. van den Hurk, A. van Meijgaard, A.P. van Ulden and H. Cuijpers. 2003. Simulation of present-day climate in RACMO2: first results and model developments. KNMI Tech. Rep. 252.

Reijmer, C.H., E. van Meijgaard and M.R. van den Broeke. 2005. Evaluation of temperature and wind over Antarctica in a regional atmospheric climate model. J. Geophys. Res., 110(D4), D04103. (10.1029/2004JD005234.)

Rogers, R.R. and M.K. Yau. 1989. A short course in cloud physics. Third edition. Woburn, MA, Butterworth-Heinemann.

Scambos, T.A., C. Hulbe, M. Fahnestock and J. Bohlander. 2000. The link between climate warming and break-up of ice shelves in the Antarctic Peninsula. J. Glaciol., 46(154), 516-530.

Schneider, D.P. and E.J. Steig. 2002. Spatial and temporal variability of Antarctic ice sheet microwave brightness temperatures. Geophys. Res. Lett., 29(20), 1964. (10.1029/2002GL015490.)

Torinesi, O., M. Fily and C. Genthon. 2003. Variability and trends of summer melt period of Antarctic ice margins since 1980 from microwave sensors. J. Climate, 16(7), 1047-1060.

Turner, J., T.A. Lachlan-Cope, J.P. Thomas and S.R. Colwell. 1995. The synoptic origins of precipitation over the Antarctic Peninsula. Antarct. Sci., 7(3), 327-337.

Turner, J., S.R. Colwell and S.A. Harangozo. 1997. Variability of precipitation over the coastal Antarctic Peninsula from synoptic observations. J. Geophys. Res., 102(D12), 13,999-14,007.

Turner, J., T.A. Lachlan-Cope, G.J. Marshall, E.M. Morris, R. Mulvaney and W. Winter. 2002. Spatial variability of Antarctic Peninsula net surface mass balance. J. Geophys. Res., 107(D13), 4173. (10.1029/2001JD000755.)

Undén, P. and 26 others. 2002. The high resolution limited area model. HIRLAM-5 scientific documentation. Norrköping, Swedish Meteorological and Hydrological Institute.

Van den Broeke, M.R. 1997. Spatial and temporal variation of sublimation on Antarctica: results of a high-resolution general circulation model. J. Geophys. Res., 102(D25), 29,76529,777 .

Van den Broeke, M.R. and N.P.M. Van Lipzig. 2003. Factors controlling the near surface wind field in Antarctica. Monthly Weather Rev., 131(4), 733-743.

Van den Broeke, M.R., C.H. Reijmer and R. van de Wal. 2005. A study of the Antarctic mass balance using automatic weather stations. J. Glaciol., 50(171), 565-583.

Van den Hurk, B. and P. Viterbo. 2003. The Torne-Kalix PILPS 2(e) experiment as a test bed for modifications to the ECMWF land surface scheme. Global Planet. Change, 38(1), 165-173.

Van Lipzig, N.P.M. and M.R. van den Broeke. 2002. A model study on the relation between atmospheric boundary-layer dynamics and poleward atmospheric moisture transport in Antarctica. Tellus, 54A(5), 497-511.

Van Lipzig, N.P.M., E. van Meijgaard and J. Oerlemans. 2002. The spatial and temporal variability of the surface mass balance in Antarctica: results from a regional climate model. Int. J. Climatol., 22(11), 1197-1217.

Van Ommen, T.D., V. Morgan and M.A.J. Curran. 2004. Deglacial and Holocene changes in accumulation at Law Dome. Ann. Glaciol., 39, 359-365.

Vaughan, D.G. and C.S.M. Doake. 1996. Recent atmospheric warming and retreat of ice shelves on the Antarctic Peninsula. Nature, 379(6563), 328-331.

Vaughan, D.G., J.L. Bamber, M.B. Giovinetto, J. Russell and A.P.R. Cooper. 1999. Reassessment of net surface mass balance in Antarctica. J. Climate, 12(4), 933-946.

White, P.W. 2001. Part IV: physical processes (CY23R4). Reading, European Centre for Medium-Range Weather Forecasts.

Winther, J.G., M.N. Jespersen and G.E. Liston. 2001. Blue-ice areas in Antarctica derived from NOAA AVHRR satellite data. J. Glaciol., 47(157), 325-334. 